\title{
The Third Sodium Binding Site of Na,K-ATPase Is Functionally Linked to Acidic pH-Activated Inward Current
}

\author{
Ciming Li, Käthi Geering, Jean-Daniel Horisberger \\ Department of Pharmacology and Toxicology, University of Lausanne, CH-1005 Lausanne, Switzerland
}

Received: 24 May 2006/Accepted: 3 October 2006

\begin{abstract}
Sodium- and potassium-activated adenosine triphosphatases (Na,K-ATPase) is the ubiquitous active transport system that maintains the $\mathrm{Na}^{+}$ and $\mathrm{K}^{+}$gradients across the plasma membrane by exchanging three intracellular $\mathrm{Na}^{+}$ions against two extracellular $\mathrm{K}^{+}$ions. In addition to the two cation binding sites homologous to the calcium site of sarcoplasmic and endoplasmic reticulum calcium ATPase and which are alternatively occupied by $\mathrm{Na}^{+}$ and $\mathrm{K}^{+}$ions, a third $\mathrm{Na}^{+}$-specific site is located close to transmembrane domains 5, 6 and 9, and mutations close to this site induce marked alterations of the voltage-dependent release of $\mathrm{Na}^{+}$to the extracellular side. In the absence of extracellular $\mathrm{Na}^{+}$and $\mathrm{K}^{+}$, $\mathrm{Na}, \mathrm{K}$-ATPase carries an acidic $\mathrm{pH}$-activated, ouabain-sensitive "leak" current. We investigated the relationship between the third $\mathrm{Na}^{+}$binding site and the $\mathrm{pH}$-activated current. The decrease (in E961A, T814A and Y778F mutants) or the increase (in G813A mutant) of the voltage-dependent extracellular $\mathrm{Na}^{+}$affinity was paralleled by a decrease or an increase in the $\mathrm{pH}$-activated current, respectively. Moreover, replacing E961 with oxygen-containing side chain residues such as glutamine or aspartate had little effect on the voltage-dependent affinity for extracellular $\mathrm{Na}^{+}$and produced only small effects on the $\mathrm{pH}$-activated current. Our results suggest that extracellular protons and $\mathrm{Na}^{+}$ions share a high field access channel between the extracellular solution and the third $\mathrm{Na}^{+}$binding site.
\end{abstract}

Key words: $\mathrm{Na}, \mathrm{K}-\mathrm{ATPase}-$ Cation binding site Voltage dependence - Proton conductance - Sitedirected mutagenesis

C. L.'s present address is: Zimmer GmbH, Sulzer-Allee 8 CH-8404 Winterthur, Switzerland.

Correspondence to: J.-D. Horisberger; email: jean-daniel. horisberger@unil.ch

\section{Introduction}

Sodium- and potassium-activated adenosine triphosphatases (Na,K-ATPase), a ubiquitous P-type ATPase, is composed of a catalytic $\alpha$-subunit and a regulatory $\beta$-subunit. Using the free energy provided by the hydrolysis of one molecule of ATP, Na,KATPase carries out the exchange of three intracellular $\mathrm{Na}^{+}$for two extracellular $\mathrm{K}^{+}$ions.

It is widely accepted that the general structure of the $\mathrm{Na}, \mathrm{K}$ pump $\alpha$-subunit (Horisberger, 2004) is similar to that of the sarcoplasmic and endoplasmic reticulum $\mathrm{Ca}^{2+}$ ATPase (SERCA) (Sweadner \& Donnet, 2001), for which high-resolution structures were obtained in E1-, E2- and ATP-bound states (Toyoshima et al., 2000; Toyoshima \& Mizutani, 2004; Toyoshima \& Nomura, 2002).

Mutagenesis studies (Feng \& Lingrel, 1995; Jewell-Motz \& Lingrel, 1993; Jorgensen, Hakansson \& Karlish, 2003; Van Huysse, Jewell \& Lingrel, 1993) together with homology modeling data (Hakansson \& Jorgensen, 2003; Ogawa \& Toyoshima, 2002) support the hypothesis that the two cation binding sites, which are alternatively occupied by $\mathrm{Na}^{+}$and $\mathrm{K}^{+}$, are homologous to the two calcium binding sites (sites I and II) of SERCA. Because $\mathrm{Na}, \mathrm{K}$-ATPase carries three $\mathrm{Na}^{+}$ions out of the cell during each transport cycle, the existence of a third $\mathrm{Na}^{+}$binding site has been postulated. We have recently provided experimental evidence indicating that the third $\mathrm{Na}^{+}$binding site is located between transmembrane (TM) domains 5, 6 and 9 ( $\mathrm{Li}$ et al., 2005). In particular, E961 in TM9, G813 and T814 in TM6 and Y778 in TM5 contribute to this site. Mutations in the third $\mathrm{Na}^{+}$-specific site result in a major alteration of the voltage-dependent charge translocating release of $\mathrm{Na}^{+}$to the extracellular side of the membrane, suggesting a close relationship between the third $\mathrm{Na}^{+}$site and the proposed 
high field extracellular ion access channel of the Na,K pump (Gadsby, Rakowski \& De Weer, 1993; Hilgemann, 1994).

Under physiological conditions, Na,K-ATPase exhibits a $3 \mathrm{Na}^{+} / 2 \mathrm{~K}^{+}$transport mode (Post \& Jolly, 1957). However, under nonphysiological conditions, noncanonical flux modes, such as $\mathrm{Na}^{+} / \mathrm{Na}^{+}$exchange and $\mathrm{K}^{+} / \mathrm{K}^{+}$exchange, can be observed (for review, see Läuger, 1991). In the absence of extracellular $\mathrm{Na}^{+}$and $\mathrm{K}^{+}$, an inward ouabain-sensitive current has been detected (Rakowski et al., 1991), and this current was increased by acidic pH (Efthymiadis, Rettinger \& Schwarz, 1993). During further investigation of this inward current in $\mathrm{Na}^{+}$loaded Xenopus oocytes, we observed that the ouabain-sensitive, $\mathrm{pH}$-activated current could be measured when protons were the only cations present in the extracellular solution and that this current was paralleled by an ouabain-sensitive intracellular acidification (Wang \& Horisberger, 1995). Based on these results, we concluded that in the absence of extracellular $\mathrm{Na}^{+}$and $\mathrm{K}^{+}$, Na,K-ATPase can mediate an inward proton current. To explain this functional property of $\mathrm{Na}, \mathrm{K}-\mathrm{ATPase}$, it was speculated that the E2 conformation with binding sites exposed to the extracellular side is accessible to protons from both sides and, thus, provides a channel-like pathway for protons. On the other hand, using ouabain-resistant mutants of Torpedo californica $\mathrm{Na}, \mathrm{K}$-ATPase in Xenopus oocytes, this inward current was proposed to be rather a consequence of an ATP-dependent reaction cycle, which could be explained by a kinetic model based on the Post-Albers scheme of the $\mathrm{Na}, \mathrm{K}$ pump with a modification derived from the gastric H,K-ATPase (Rettinger, 1996).

More recently, Vasilyev, Khater \& Rakowski (2004) described the effects of extracellular $\mathrm{pH}$ on ouabain-sensitive pre-steady-state and steady-state currents. They concluded that both $\mathrm{H}^{+}$and $\mathrm{Na}^{+}$can permeate through a conducting pathway activated by low $\mathrm{pH}$ when $\mathrm{Na}, \mathrm{K}-\mathrm{ATPase}$ is in the E2P conformation. In this conformation, Na,K-ATPase provides a high field channel-like pathway through which the voltage-dependent charge translocation of $\mathrm{Na}^{+}$ occurs (Gadsby et al., 1993; Hilgemann, 1994). In consequence, the question arises whether extracellular protons use the same pathway as extracellular sodium during their translocation through the protein. In this study, we investigated the functional relation between the third $\mathrm{Na}^{+}$binding site and the acidic pH-activated current of Na,K-ATPase by comparing the voltage-dependent inhibition of the $\mathrm{Na}, \mathrm{K}$ pump current by extracellular $\mathrm{Na}^{+}$to the ouabain-sensitive current in $\mathrm{Na}^{+}$- and $\mathrm{K}^{+}$-free solution at $\mathrm{pH} 6$ of rat $\mathrm{Na}, \mathrm{K}-\mathrm{ATPase}$ expressed in Xenopus oocytes.

\section{Materials and Methods}

\section{Site-Directed Mutagenesis and Chimeras}

The rat Na,K-ATPase $\alpha_{1}$-subunit was modified by silence mutagenesis to introduce one restriction site $(A c c \mathrm{I})$ at nucleotide position 2893 , and then point mutations were introduced by the polymerase chain reaction-based method described by Nelson and Long (1989). The insert of TM9 was subcloned into a pSD5 vector using $A c c \mathrm{I} /$ DraIII restriction sites, and the insert of TM5 and TM6 was subcloned between $A c c \mathrm{I}$ and $K p n \mathrm{I}$. The nucleotide sequences of all constructs were confirmed by dideoxy sequencing. cDNAs for rat $\alpha_{1}$ - and $\beta_{1}$-subunits were kindly provided by J. Lingrel (Department of Molecular Genetics, Biochemistry and Microbiology, University of Cincinnati, $\mathrm{OH})$.

\section{Protein Expression in Xenopus Oocytes}

cRNAs were obtained by in vitro transcription (Melton et al., 1984). Stage V-VI Xenopus oocytes were obtained as described (Geering et al., 1996). Oocytes were injected with cRNAs coding for the wildtype and mutant rat $\mathrm{Na}, \mathrm{K}$-ATPase $\alpha_{1}$-subunit (10 ng/oocyte) together with cRNAs for wild-type rat $\beta_{1}$-subunit ( $1 \mathrm{ng} /$ oocyte). Oocytes were then incubated for $24 \mathrm{~h}$ at $19^{\circ} \mathrm{C}$ in a modified Barth solution (MBS) in the presence of $0.8-1 \mathrm{mCi} / \mathrm{ml}{ }^{35} \mathrm{~S}$-methionine (Easy Tag Express $\left[{ }^{35} \mathrm{~S}\right]$ Protein Labeling Kit, specific activity 1,175 $\mathrm{Ci} / \mathrm{mmol}$; Perkin-Elmer, Wellesley, MA) and subjected to a $24-\mathrm{h}$ pulse and a 48-h chase period in MBS containing $10 \mathrm{~mm}$ cold methionine. After the pulse and chase periods, oocyte extracts were prepared as previously described (Geering et al., 1996) with a digitonin-containing buffer $(0.5 \% \mathrm{w} / \mathrm{v}$ final concentration) and subjected to immunoprecipitations with $\mathrm{Na}, \mathrm{K}$-ATPase $\alpha$ antibodies (Girardet et al., 1981) under nondenaturing conditions (Geering et al., 1996). Immunoprecipitated proteins were separated on sodium dodecyl sulfate (SDS)-polyacrylamide gels (5-13\% gradients) and revealed by fluorography.

\section{Electrophysiological Measurements}

Two to three days after injection of Xenopus oocytes with cRNAs coding for wild-type or mutant rat Na,K-ATPase $\alpha_{1}$-subunits (10 ng/oocyte) together with cRNAs for the rat Na,K-ATPase $\beta_{1}$-subunit ( $1 \mathrm{ng} /$ oocyte), electrophysiological measurements were performed using the two-electrode voltage-clamp technique with a Dagan TEV-200 voltage-clamp apparatus (Dagan, Minneapolis, $\mathrm{MN}$ ). Before electrophysiological measurements, oocytes were loaded with $\mathrm{Na}^{+}$by overnight exposure to a $\mathrm{K}^{+}$-free solution containing $1 \mu \mathrm{M}$ ouabain to inhibit the endogenous oocyte $\mathrm{Na}, \mathrm{K}$ ATPase (Horisberger et al., 2004). Current-voltage (I-V) curves were recorded by imposing a series of 250 -ms voltage steps every 20 $\mathrm{m} V$ between -130 and $30 \mathrm{mV}$ and analyzed using the Digidata/ Pclamp package of Axon Instruments (Union City, CA). The composition of the control solution was $92.4 \mathrm{~mm} \mathrm{Na}{ }^{+}, 0.82 \mathrm{~mm}$ $\mathrm{Mg}^{2+}, 5 \mathrm{~mm} \mathrm{Ba}^{2+}, 0.41 \mathrm{~mm} \mathrm{Ca}{ }^{2+}, 10 \mathrm{~mm}$ tetraethylammonium $\left(\mathrm{TEA}^{+}\right), 22.4 \mathrm{mM} \mathrm{Cl}^{-}, 2.4 \mathrm{~mm} \mathrm{HCO}^{3-}, 10 \mathrm{~mm}$ 4-(2-hydroxyethyl)1-piperazineethanesulfonic acid (HEPES) and $80 \mathrm{~mm}$ gluconate ( $\mathrm{pH}$ 7.4). A low-chloride solution and $\mathrm{K}^{+}$channel blockers (barium and TEA) were used to minimize the oocyte $\mathrm{Cl}^{-}$conductance and the non-pump-related $\mathrm{K}^{+}$currents (Horisberger et al., 2004).

\section{Measurements of the Apparent Affinity for Extracellular $\mathrm{K}^{+}$}

The apparent affinity for extracellular $\mathrm{K}^{+}$was calculated from the currents induced by addition of $0.02,0.1,0.5$ and $5 \mathrm{mM} \mathrm{K}^{+}$in 
the absence of extracellular $\mathrm{Na}^{+}$or $0.3,1.0,3.0$ and $10.0 \mathrm{mM} \mathrm{K}^{+}$ in the presence of $100 \mathrm{~mm} \mathrm{Na}^{+}$. The apparent affinity for extracellular $\mathrm{K}^{+}$of the G813A mutant was calculated from currents induced by $1,3,10$ and $50 \mathrm{~mm} \mathrm{~K}^{+}$in the presence of extracellular $\mathrm{Na}^{+}$. As described earlier (Jaisser et al., 1994), the $\mathrm{K}^{+}$half-activation constant $\left(K_{1 / 2} \mathrm{~K}^{+}\right)$was determined by fitting the Hill equation parameters to the $\left[\mathrm{K}^{+}\right]_{o}-I$ curve using a Hill coefficient of 1.6 for measurements performed in the presence of extracellular $\mathrm{Na}^{+}$and 1.0 for those performed in the absence of extracellular $\mathrm{Na}^{+}$.

\section{Effect of Extracellular $\mathrm{Na}^{+}$on the $\mathrm{K}^{+}$-Induced Pump Current}

To estimate the affinity of the extracellular $\mathrm{Na}^{+}$binding site, we measured the outward current induced by a nonsaturating concentration of $\mathrm{K}^{+}(1 \mathrm{mM})$ in a nominally sodium-free, $N$-methyl-Dglucamine/HCl-containing solution and in solutions containing 100 mм $\mathrm{Na}^{+}$, as described previously (Horisberger \& Kharoubi-Hess, 2002).

\section{Acidic pH-Activated, Ouabain-Sensitive Pump Current}

To measure the amplitude of the acidic $\mathrm{pH}$-activated, ouabainsensitive pump current, we first measured the current activated by $5 \mathrm{mM} \mathrm{K}^{+}$in a nominally $\mathrm{Na}^{+}$-free solution and then, after removing $\mathrm{K}^{+}$, exposed the oocyte to $\mathrm{Na}^{+}$- and $\mathrm{K}^{+}$-free solution titrated to $\mathrm{pH} 6.0$ and measured the current inhibited by $2 \mathrm{~mm}$ ouabain (Wang \& Horisberger, 1995). All $\mathrm{K}^{+}$-induced or ouabainsensitive current values are expressed as normalized to the current induced by the maximal $\mathrm{K}^{+}$concentration at $-50 \mathrm{mV}$ measured in the same oocyte.

For all electrophysiological measurements, statistical analysis of differences between the mean values in several groups were performed by one-way analysis of variance followed by a Bonferroni posttest for multiple comparisons.

\section{Results}

To study the functional relationship between the proton current and the third $\mathrm{Na}^{+}$binding site, we studied the following $\mathrm{Na}, \mathrm{K}$-ATPase $\alpha$-subunit mutants that have been shown to influence extracellular $\mathrm{Na}^{+}$binding: E961A (TM9), G813A (TM6), T814A (TM6), Y778F (TM5) and, as a negative control, E960A (TM9) (Li et al., 2005). Moreover, we produced E961Q and E961D mutants to mimic the polar property of the glutamate side chain. The relative positions of mutated residues are schematically presented in Figure 1A. For all mutants, we tested the expression level, the effects on the apparent $\mathrm{K}^{+}$ affinity, the effects on the extracellular $\mathrm{Na}^{+}$affinity and the ouabain-sensitive currents at $\mathrm{pH}$ 6.0.

\section{Expression of Na,K-ATPase $\alpha$ Mutants}

To test protein expression levels, $\alpha$ mutants were expressed in Xenopus oocytes together with rat $\beta$-subunits, metabolically labeled and immunoprecipitated with an $\alpha$ antibody under nondenaturing conditions. All mutants were expressed to a similar extent as the wild-type $\alpha$-subunit (Fig. 1B). All $\alpha$ mutants were properly folded since they were able to associate with the $\beta$-subunit and correctly routed to the plasma membrane as reflected by the processing of the $\beta$-subunit from the core glycosylated to the fully glycosylated form during the chase period (Geering, 2001). The $\alpha$-subunit was present in similar amounts after a $48-\mathrm{h}$ chase, indicating that it was stable, as expected from its association with the $\beta$ subunit (Geering, 2001). In addition, in the presence of $100 \mathrm{~mm}$ extracellular $\mathrm{Na}^{+}$at $-50 \mathrm{~m} V$, these $\alpha$ mutants were expressed as functional proteins at the plasma membrane as they produced large $\mathrm{K}^{+}$-activated pump currents $\left(I_{\max }\right)$ as wild-type $\alpha$-subunits (Fig. 1C).

\section{Mutational Effects on the Apparent Affinity for $\mathrm{K}^{+}$in the Absence and Presence of Extracellular $\mathrm{NA}^{+}$}

We previously observed that the E960A mutant of the $\mathrm{Na}, \mathrm{K}$-ATPase $\alpha$-subunit has little effect on the apparent affinity for extracellular $\mathrm{K}^{+}\left(K_{1 / 2} \mathrm{~K}^{+}\right)$but, in contrast, the E961A mutant exhibited a strong increase in $K_{1 / 2} \mathrm{~K}^{+}$only in the presence of extracellular $\mathrm{Na}^{+}$. We showed that this effect was due to a lower affinity for competing extracellular $\mathrm{Na}^{+}(\mathrm{Li}$ et al., 2005).

We now studied the kinetics of $\mathrm{K}^{+}$activation in the three other mutants, G813A, T814A and Y778F, and in two new mutants, E961Q and E961D, in the absence (Fig. 2) and in the presence of extracellular $\mathrm{Na}^{+}$(Fig. 3). In the absence of extracellular $\mathrm{Na}^{+}$, two of the mutations in M9 (E960A and E961A) showed no effect (Fig. 2A) and two other mutations of the same residue in M9 (E961Q and E961D) produced a small (approximately twofold) reduction of the apparent affinity for extracellular $\mathrm{K}^{+}$(Fig. 2B). On the other hand, the three mutations in M5 and M6 (G813A, T814A and Y778F) resulted in a large (four- to sixfold) decrease of this parameter (Fig. 2A).

In the presence of extracellular $\mathrm{Na}^{+}$, we observed no effect of the E960A mutation and a large effect of the E961A mutation due to the effect of extracellular $\mathrm{Na}^{+}$binding, as previously described (Li et al., 2005). The T814A and Y778F mutants increased the $K_{1 / 2} \mathrm{~K}^{+}$over the whole potential range, as expected from the lower intrinsic affinity for extracellular $\mathrm{K}^{+}$, and showed a flattening of the $K_{1 / 2}$ $\mathrm{K}^{+} v s$. potential curve (Fig. 3A, the increase in $K_{1 / 2}$ $\mathrm{K}^{+}$values between -50 and $-130 \mathrm{~m} V$ was $100 \%, 20 \%$ and $30 \%$ in wild-type, T814A and Y778A, respectively) that can be attributed to a reduced inhibitory effect of external $\mathrm{Na}^{+}$at high negative membrane potential. The G813A mutant showed a very large increase in $K_{1 / 2} \mathrm{~K}^{+}$mainly at negative membrane potentials (Fig. 3B). We can interpret these results 
Fig. 1. Expression of $\mathrm{Na}, \mathrm{K}-\mathrm{ATPase} \alpha$-subunit mutants in Xenopus oocytes. (A) Schematic representation of the disposition of the transmembrane domains of the $\mathrm{Na}, \mathrm{K}$-ATPase $\alpha$-subunit in a view from the intracellular side with indications of the residues which have been mutated. Black dots in sites I and II indicate the position of cation binding sites I and II, which are occupied alternatively by $\mathrm{K}^{+}$and $\mathrm{Na}^{+}$. The black star indicates the position of the $\mathrm{Na}^{+}-$ specific binding site III ( $\mathrm{Li}$ et al., 2005). White circles are the transmembrane domains implicated in the third $\mathrm{Na}^{+}$binding site with the backbone and side chain oxygen atoms implicated in the coordination of the $\mathrm{Na}^{+}$ion site based on homology modeling (Ogawa \& Toyoshima, 2002). (B) Protein expression of Na,KATPase $\alpha$-subunit mutants in Xenopus oocytes. Xenopus oocytes were injected with wild-type or mutant $\alpha$-subunit (10 ng) cRNA together with $\beta_{1}(1 \mathrm{ng}) \mathrm{cRNA}$, metabolically labeled for $24 \mathrm{~h}$ with $\left[{ }^{35} \mathrm{~S}\right]$ methionine and subjected to a 48 -h chase period. Digitonin extracts were prepared after the pulse and the chase periods, and immunoprecipitation was performed in nondenaturing conditions using an anti- $\alpha$-subunit antibody. Immunoprecipitates were separated on SDS-polyacrylamide gels. $f \beta 1$, fully glycosylated form of $\beta_{1}$-subunit; $\mathrm{c} \beta 1$, core glycosylated form of $\beta_{1}$-subunit. (C) Functional expression of wild-type and mutant $\mathrm{Na}, \mathrm{K}-\mathrm{ATPase}$ in oocytes injected with $10 \mathrm{ng}$ of wild-type or mutant $\alpha$-subunit cRNA together with $1 \mathrm{ng}$ of $\beta_{1}$-subunit cRNA. The outward current (mean \pm standard error) resulting from activation of $\mathrm{Na}, \mathrm{K}-\mathrm{AT}$ Pase by addition of $10 \mathrm{mM} \mathrm{K}^{+}$to a previously $\mathrm{K}^{+}$-free bath solution, at a holding potential of $-50 \mathrm{mV}$, is reported for wild-type (WT) and each mutant. The number of measurements is between 6 and 17 in each group.

from the combined effects of a reduction in the intrinsic affinity for extracellular $\mathrm{K}^{+}$(Fig. 2A) and an increase in the voltage-dependent affinity for competing extracellular $\mathrm{Na}^{+}$(Li et al., 2005). Finally, replacement of E961 by residues with oxygen-containing side chains such as glutamine and aspartate entailed only a small increase of $K_{1 / 2} \mathrm{~K}^{+}$values without marked modification of the voltage dependence of this parameter, suggesting the absence of a large effect on the affinity for extracellular $\mathrm{Na}^{+}$ (Fig. 3C).

\section{Inhibition of $\mathrm{K}^{+}$-Activated Pump Current by Extracellular $\mathrm{NA}^{+}$}

As reported earlier ( $\mathrm{Li}$ et al., 2005), mutations E961A, Y778F, G813A and T814A resulted in considerable perturbations of the voltage-dependent affinity for extracellular $\mathrm{Na}^{+}$. We estimated the voltage-dependent binding of $\mathrm{Na}^{+}$to its extracellular binding site by measuring the effect of extracellular $\mathrm{Na}^{+}(100 \mathrm{~mm})$ on the current induced by a nonsaturating $(1 \mathrm{~mm}) \mathrm{K}^{+}$concentration. As described earlier in the wild-type pump (Horisberger \& Kharoubi-Hess, 2002), we observed (see Fig. 4) that $100 \mathrm{~mm}$ extracellular $\mathrm{Na}^{+}$inhibited the $1 \mathrm{~mm} \mathrm{~K}{ }^{+}$induced current by about $40 \%$ in the low membrane potential range $(-50$ to $+30 \mathrm{mV})$ with little voltage dependence, while at membrane potential more negative than $-50 \mathrm{~m} V$ the inhibition was clearly voltage-

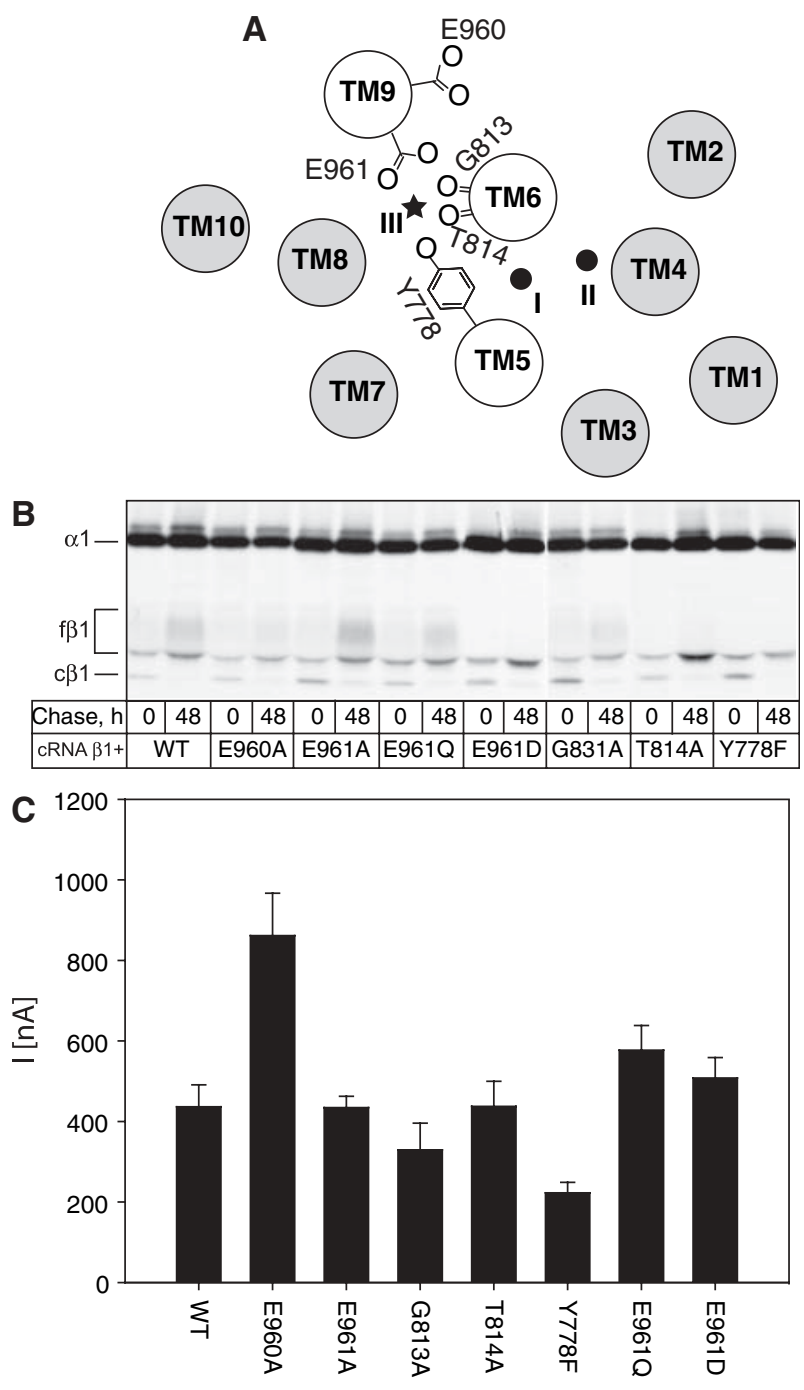

dependent, reaching about $80 \%$ at $-130 \mathrm{mV}$. The effects of extracellular $\mathrm{Na}^{+}$on E960A, E961Q and E961D mutants were roughly similar to those on the wild type. As shown earlier ( $\mathrm{Li}$ et al., 2005), extracellular $\mathrm{Na}^{+}$produced only a small $(\sim 20 \%)$ inhibition in the E961A mutant without any voltage dependence over the whole potential range. The T814A and Y778 F mutants were inhibited by extracellular $\mathrm{Na}^{+}$slightly more than wild type in the low potential range, but there was hardly any voltage-dependent component. Finally, G813A was much more strongly inhibited by extracellular $\mathrm{Na}^{+}$ with a large and voltage-dependent inhibition in the depolarized membrane voltage range and nearly complete inhibition at membrane potentials more negative than $-80 \mathrm{~m} V$.

As shown by model fitting in Figure 4, these results can be interpreted using a simple two-step $\mathrm{Na}^{+}$ binding process similar to the model proposed by Hilgemann (1994) with an electrogenic and voltagedependent binding of one $\mathrm{Na}^{+}$ion and little or no voltage dependence for the binding of the two other 

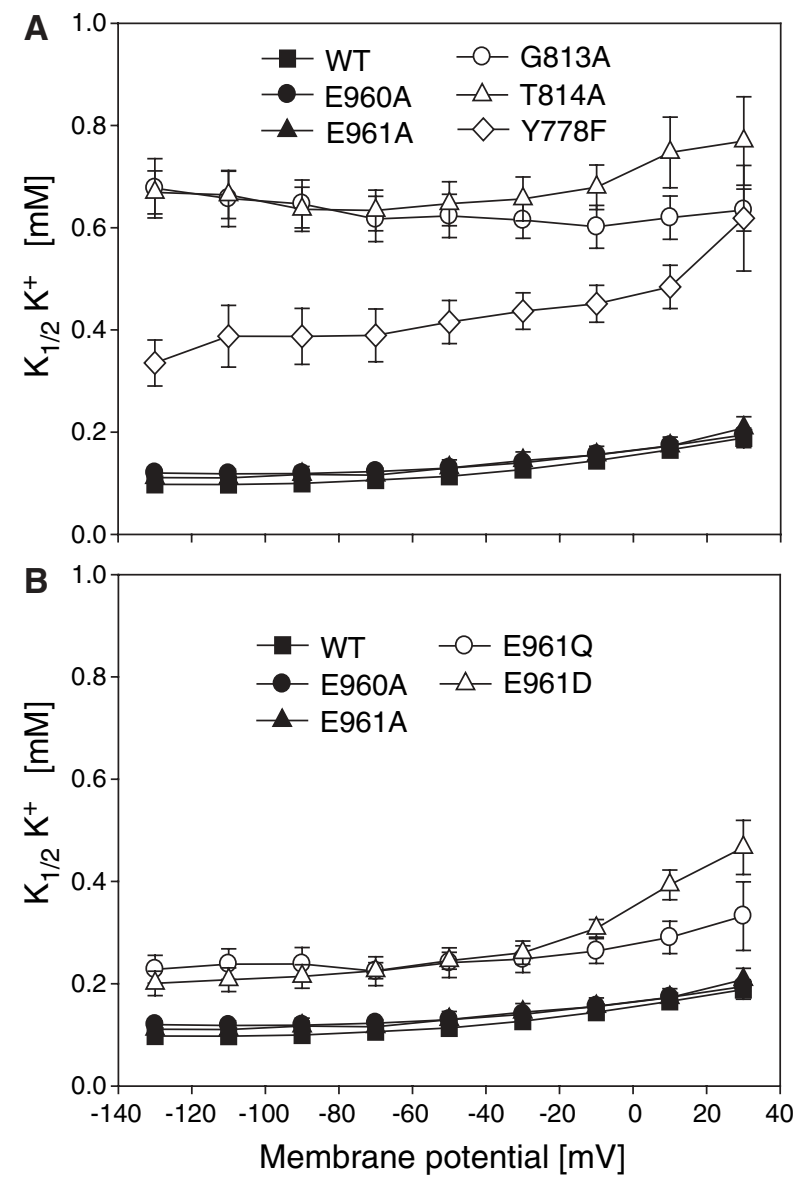

Fig. 2. Apparent affinity for $\mathrm{K}^{+}$in the absence of extracellular $\mathrm{Na}^{+} .(A, B)$ Potassium half-activation constant $\left(K_{1 / 2} \mathrm{~K}^{+}\right)$measured in the absence of extracellular $\mathrm{Na}^{+}$for wild-type (WT) and mutant $\alpha$-subunits. For clarity, the results are presented in two graphs. Means \pm standard error of 7-21 oocytes from two to six different batches are shown. Statistical analysis indicated the following significant differences for the $K_{1 / 2} \mathrm{~K}^{+}$values measured at $-50 \mathrm{~m} V$ : WT vs. G813A, $P<0.001$; WT vs. T814A, $P<0.001$; WT vs. Y778F, $P<0.001$; WT vs. E961Q, $P<0.001$; WT vs. E961D, $P<0.001$.

$\mathrm{Na}^{+}$ions. The position of the electrogenic release of the first $\mathrm{Na}^{+}$ion in the $\mathrm{Na}, \mathrm{K}$ pump transport cycle is described below.

\section{Acidic pH-Activated, Ouabain-Sensitive Pump Current}

In the absence of extracellular $\mathrm{Na}^{+}$and $\mathrm{K}^{+}$, an ouabain-sensitive inward pump current can be recorded, and this current is increased by low $\mathrm{pH}$ (Efthymiadis et al., 1993; Rakowski et al., 1991; Wang \& Horisberger, 1995). Figure 5 shows the $I-V$ curves of the ouabain-sensitive current under these conditions in the wild-type $\mathrm{Na}, \mathrm{K}-\mathrm{ATP}$ ase and several mutants. The wild-type $\alpha$-subunit and the E960A mutant exhibited an ouabain-sensitive current with characteristics similar to those reported earlier (Vasilyev et al., 2004; Wang \& Horisberger, 1995),
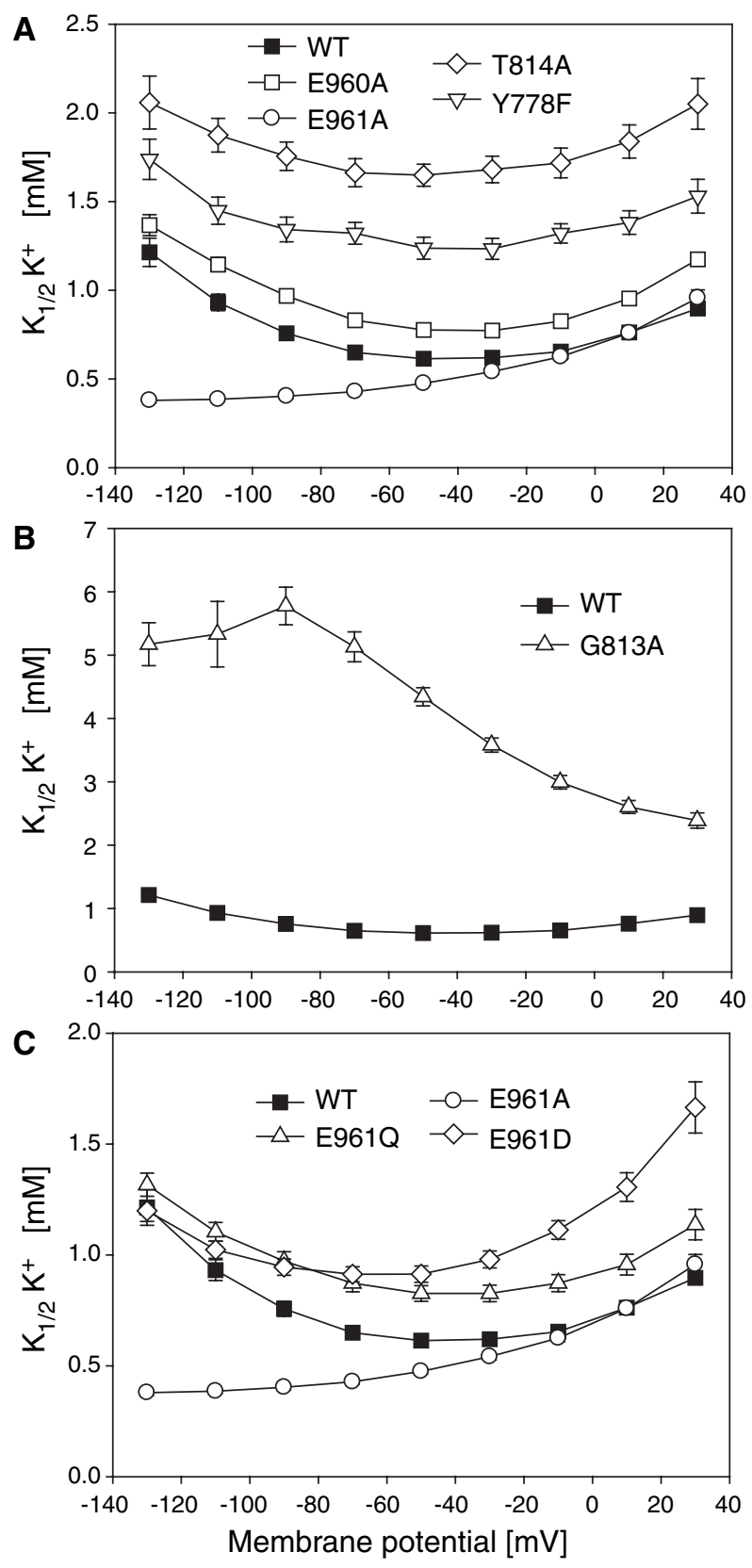

Fig. 3. Apparent affinity for $\mathrm{K}^{+}$in the presence of extracellular $\mathrm{Na}^{+}$. Potassium half-activation constant $\left(K_{1 / 2} \mathrm{~K}^{+}\right)$measured in the presence of $100 \mathrm{~mm}$ extracellular $\mathrm{Na}^{+}$for wild-type (WT) and mutant $\alpha$-subunits. For clarity, results for the various mutants are presented in three graphs; in all cases, mutants (open symbols) are compared to wild-type (solid symbols). Note that the $y$ scale is different in $B$. Statistical analysis indicated the following significant differences for the values measured at $-50 \mathrm{~m} V$ : wild-type $v s$. G813A, $P<0.001$; WT vs. T814A, $P<0.001$; WT vs. Y778F, $P<0.001$. The voltage dependence of the $K_{1 / 2} \mathrm{~K}^{+}$was clearly different between the wild-type and the E961 A mutant $(A, P<0.001$ for comparison of the slope of the $K_{1 / 2} \mathrm{~K}^{+}$vs. $V_{\mathrm{m}}$ relationship between -130 and $-50 \mathrm{~m} V$ ). Means \pm standard error of 7-17 oocytes from two to five different batches are shown. Some error bars are covered by the symbols.

and the amplitude of this current was similar (Fig. 5A). The G813A mutant, which has a higher voltage-dependent affinity for extracellular $\mathrm{Na}^{+}$, had 


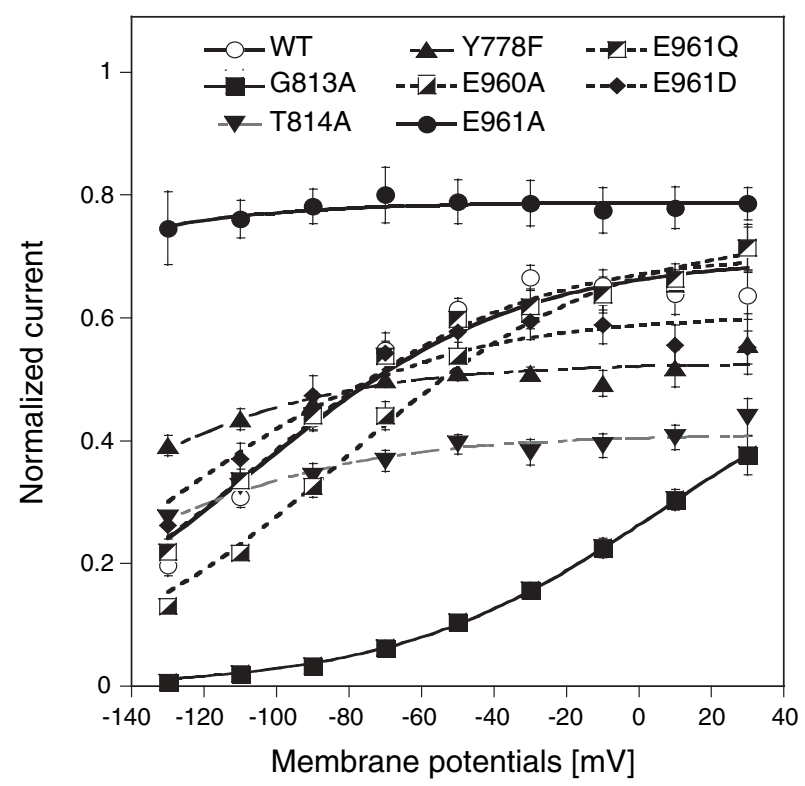

Fig. 4. Voltage-dependent inhibition of pump currents by extracellular $\mathrm{Na}^{+}$. The pump current activated by addition of $1 \mathrm{~mm} \mathrm{~K}^{+}$to a previously $\mathrm{K}^{+}$-free solution was first recorded without extracellular $\mathrm{Na}^{+}$and then in the presence of $100 \mathrm{~mm}$ extracellular $\mathrm{Na}^{+}$. The graph shows the residual $\mathrm{K}^{+}$-activated pump currents in the presence of $100 \mathrm{~mm}$ extracellular $\mathrm{Na}^{+}$normalized to the current recorded in the absence of extracellular $\mathrm{Na}^{+}$. The results are the mean \pm standard error of 7-18 oocytes from two to five different batches. At $-130 \mathrm{~m} V$, wild type (WT) vs. E961A, $P<0.001$; WT vs. E961D, $P<0.05$; WT vs. G813A, $P<0.001$; WT vs. T814A, $P<0.001$; WT vs. Y778F, $P<$ 0.001 . The following model was fitted to the data to obtain values for voltage-dependent and voltage-independent $\mathrm{Na}^{+}$binding affinity. According to the sequential binding of extracellular $\mathrm{Na}^{+}$proposed by Hilgemann (1994), we assumed a simple two-step Na ${ }^{+}$binding reaction as shown at the top of the figure. The mole fraction of the E0 state, i.e., the active state that can bind $\mathrm{K}^{+}$and carry on the transport cycle, can be calculated as follows: $\mathrm{EO}=\frac{K d_{1} K d_{2}(V)}{\left[\mathrm{Na}^{2}+K d_{2}(V)[\mathrm{Na}]+K d_{1}, K d_{2}(V)\right.}$ where $K_{\mathrm{d} 1}$ is the voltage-independent binding constant of the first reaction and $K_{\mathrm{d} 2}(V)$ is the voltage-dependent binding constant of the second reaction. The voltage dependence of $K_{\mathrm{d} 2}(V)$ was assumed to be determined as follows: $K d_{2}(V)=K d_{2}(0) \cdot \exp \left(\delta V \frac{F}{R T}\right)$ where $K_{\mathrm{d} 2}(0)$ is the value of $K_{\mathrm{d} 2}$ at $0 \mathrm{~m} V$ and $\delta$ is the dielectric coefficient for $\mathrm{Na}^{+}$ binding at the second reaction. The value of $\delta$ was set at 0.7 from published results (Apell $\&$ Karlish, 2001). The following best fitting values of $K_{\mathrm{d} 1}$ and $K_{\mathrm{d} 2}(0)$ were obtained:

\begin{tabular}{lrrr}
\hline & $K_{\mathrm{d} 1}$ & $K_{\mathrm{d} 2} V(0)$ & $\mathrm{mM}$ \\
\hline WT & 230 & 572 & $\mathrm{mM}$ \\
G813A & 133 & 37 & $\mathrm{mM}$ \\
T814A & 70 & 4,152 & $\mathrm{mM}$ \\
Y778F & 111 & 4,694 & $\mathrm{mM}$ \\
E960A & 279 & 249 & $\mathrm{mM}$ \\
E961A & 373 & 14,457 & $\mathrm{mM}$ \\
E961Q & 240 & 548 & $\mathrm{mM}$ \\
E961D & 153 & 1,398 & $\mathrm{~m}$ \\
\hline
\end{tabular}

This confirms the strong decrease of the voltage-dependent affinity for extracellular $\mathrm{Na}^{+}$in the E961A, T814A and Y778F mutants and the opposite effect for the G813A mutant.

a ouabain-sensitive $I-V$ curve of similar shape but with a significantly larger amplitude at large negative potentials. In contrast, E961A, T814A and Y778F mutants, which have a lower voltage-dependent affinity for extracellular $\mathrm{Na}^{+}$than the wild-type $\alpha$ subunit, showed only small inward currents. Finally, substitutions of glutamate (E961Q) by glutamine and aspartate (E961D), demonstrating no or little effect on the voltage-dependent affinity for extracellular $\mathrm{Na}^{+}$, also had little effect on the amplitude of ouabain-sensitive inward currents (Fig. 5B).

To investigate the relationship between inhibition by extracellular $\mathrm{Na}^{+}$and the acidic $\mathrm{pH}$-activated pump current, we compared the ouabain-sensitive inward current in $\mathrm{K}^{+}$-free and $\mathrm{Na}^{+}$-free $\mathrm{pH} \quad 6.0$ solutions (Fig. 5) for wild-type and mutant $\alpha$-subunits with the voltage-dependent and voltage-independent inhibition of the $\mathrm{Na}, \mathrm{K}$ pump current induced by $100 \mathrm{~mm}$ extracellular $\mathrm{Na}^{+}$(Fig. 4). As shown in Figure 6 , there was a highly significant correlation between the amplitude of the acidic $\mathrm{pH}$-activated inward current at $-130 \mathrm{mV}$ and the voltage-dependent inhibition by extracellular $\mathrm{Na}^{+}$but no obvious relationship between the the amplitude of the acidic $\mathrm{pH}$-activated inward current and the voltageindependent inhibition by extracellular $\mathrm{Na}^{+}$. 

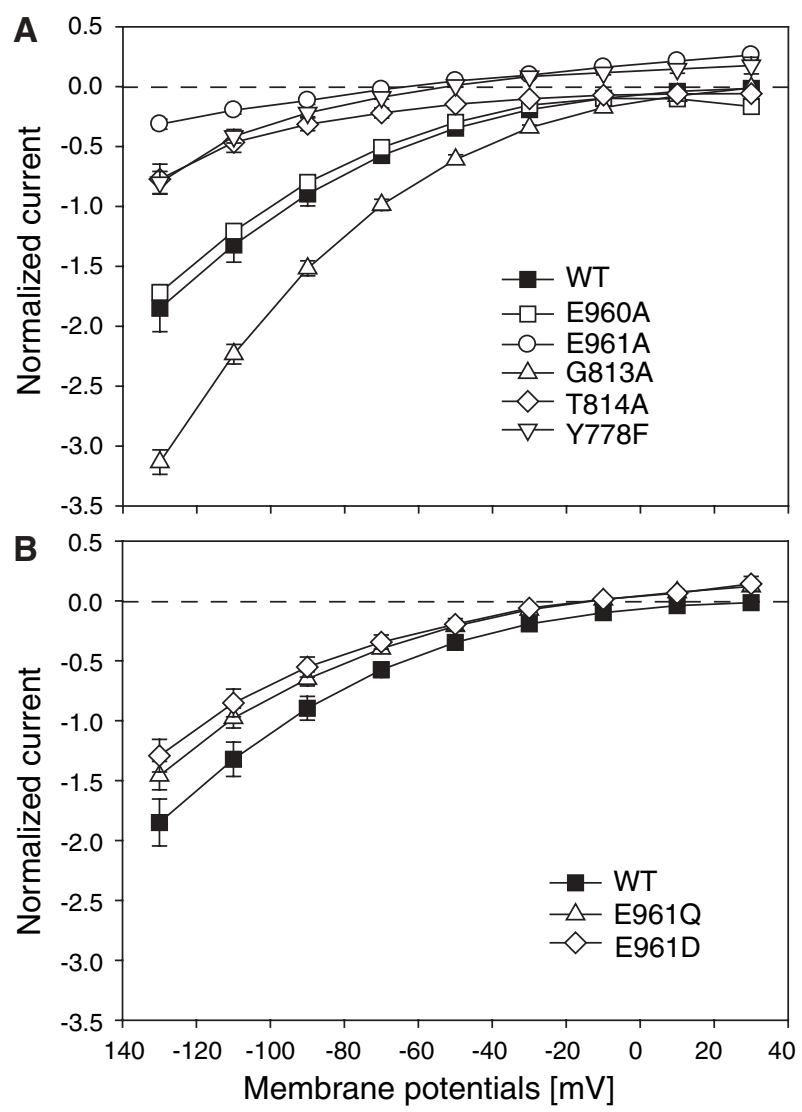

Fig. 5. Acidic pH-activated, ouabain-sensitive pump currents. The $\mathrm{Na}, \mathrm{K}$ pump current activated by $5 \mathrm{~mm} \mathrm{~K}^{+}$in $\mathrm{Na}^{+}$-free solution was first measured, then the $\mathrm{pH}$ of the solution was changed to 6.0 and $I-V$ curves were recorded before and after addition of $2 \mathrm{~mm}$ ouabain. The differences of currents recorded at $\mathrm{pH} 6$ without or with $2 \mathrm{~mm}$ ouabain, normalized to the pump current activated by $5 \mathrm{mM} \mathrm{K}^{+}$, are shown in two panels for clarity; in both cases, mutants (open symbols) are compared with wild- type (WT, solid symbols). Data are mean \pm standard error of 8-19 oocytes from two to six different batches. Statistical analysis indicates the following significant differences for the values measured at $-130 \mathrm{mV}$ : WT vs. E961A, $P<0.001$; WT vs. G813A, $P<0.001$; WT vs. T814A, $P<0.001$; WT vs. Y778F, $P<0.001$.

\section{Discussion}

Previous experimental evidence implicated E961 (TM9), G813 and T814 (TM6) and Y778 (TM5) in the $\mathrm{Na}^{+}$-specific site corresponding to $\mathrm{Na}^{+}$site III of $\mathrm{Na}, \mathrm{K}-\mathrm{ATPase}$ proposed by Ogawa \& Toyoshima (2002). Mutations of these residues resulted in large alterations of the $\mathrm{Na}^{+}$release to the extracellular side and in the modification of the activation by intracellular $\mathrm{Na}^{+}$(Li et al., 2005). As illustrated in Figure 7, the voltage-dependent affinity of extracellular $\mathrm{Na}^{+}$is due to the movement of the first $\mathrm{Na}^{+}$ ion to be released to the extracellular medium. Here, we show that substitutions of E961 by mimetic residues such as glutamine or aspartate have only small effects on the voltage-dependent affinity for extracellular $\mathrm{Na}^{+}$. The results obtained with the E961Q
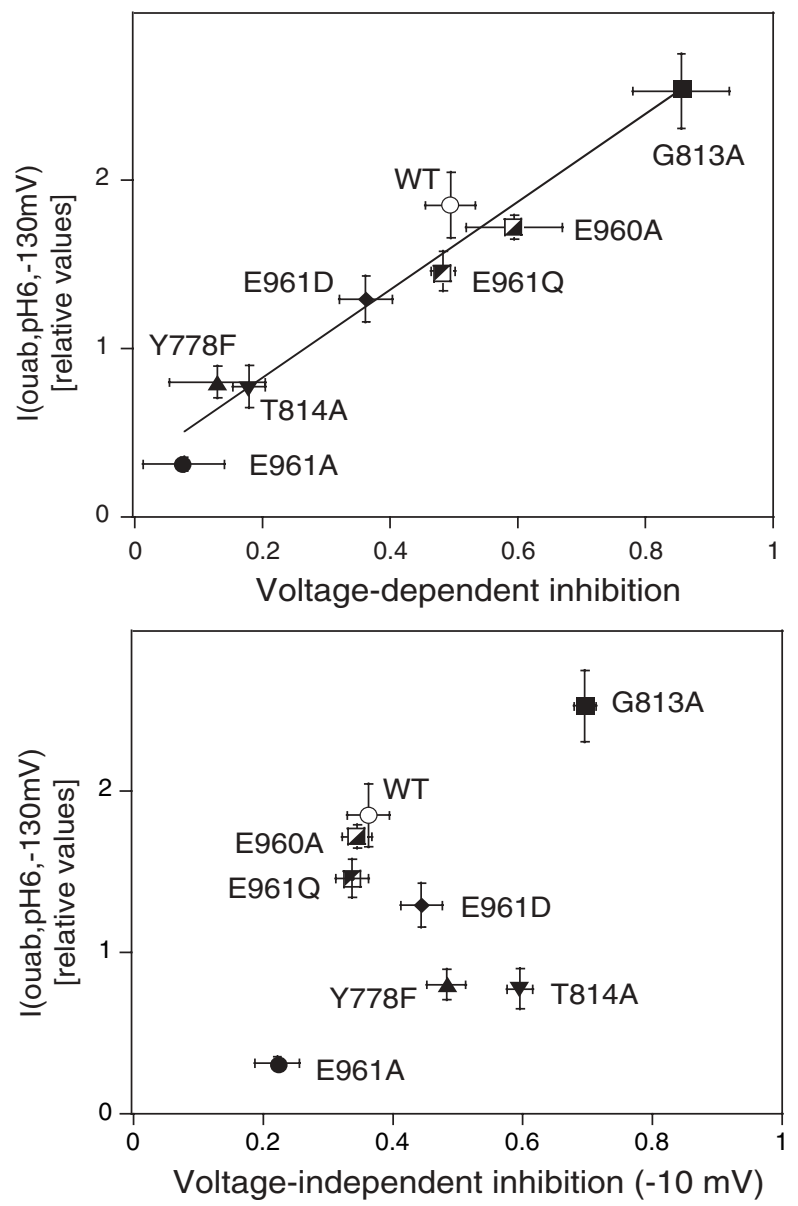

Fig. 6. Correlation between inhibition of the $\mathrm{Na}, \mathrm{K}$ pump by extracellular $\mathrm{Na}^{+}$and the inward proton current. $(A)$ The normalized ouabain-sensitive current at $\mathrm{pH} 6.0$ and $-130 \mathrm{mV}$ (original data in Fig. 5) is reported as a function of the voltage dependence of the inhibition by $100 \mathrm{~mm}$ extracellular $\mathrm{Na}^{+}$(original data in Fig. 4) between -10 and $-110 \mathrm{~m} V$, calculated as follows: $1-I_{100 \mathrm{Na}}(-10 \mathrm{~m} V) / I_{100 \mathrm{Na}}(-110 \mathrm{~m} V)$ where $I_{100 \mathrm{Na}}(-10 \mathrm{~m} V)$ is the remaining current in the presence of $100 \mathrm{~mm} \mathrm{Na}^{+}$at $-10 \mathrm{mV}$ and $I_{100 \mathrm{Na}}(-110 \mathrm{mV})$ is the remaining current in the presence of $100 \mathrm{~mm}$ $\mathrm{Na}^{+}$at $-110 \mathrm{mV}$. Each data point represents the mean \pm standard error of a group of measurements with wild-type or mutant $\mathrm{Na}, \mathrm{K}-\mathrm{ATPase}$. $(B)$ The normalized ouabain-sensitive current at $\mathrm{pH}$ 6.0 and $-130 \mathrm{mV}$ (original data in Fig. 5) is reported in a similar manner as a function of the non-voltage-dependent inhibition by $100 \mathrm{~mm} \mathrm{Na}^{+}$taken as the inhibition at $-10 \mathrm{mV}$ (original data in Fig. 4). The voltage-dependent inhibition $(A)$ is strongly correlated with the ouabain-sensitive, acid-induced current $\left(R^{2}=0.9544, P\right.$ $<0.001$ ), while the voltage-independent inhibition (at $-10 \mathrm{~m} V, B$ ) is not.

mutation indicate that, rather than the negatively charged side chain, it is the presence of oxygen or the potential to form hydrogen bonds that is important for this functional property. The results with the E961D mutation indicate that the length of the side chain is not important.

The four mutations in TM9 (E960A, E961A, E961D and E961Q) had no or rather limited direct effects on the apparent affinity for extracellular $\mathrm{K}^{+}$. 


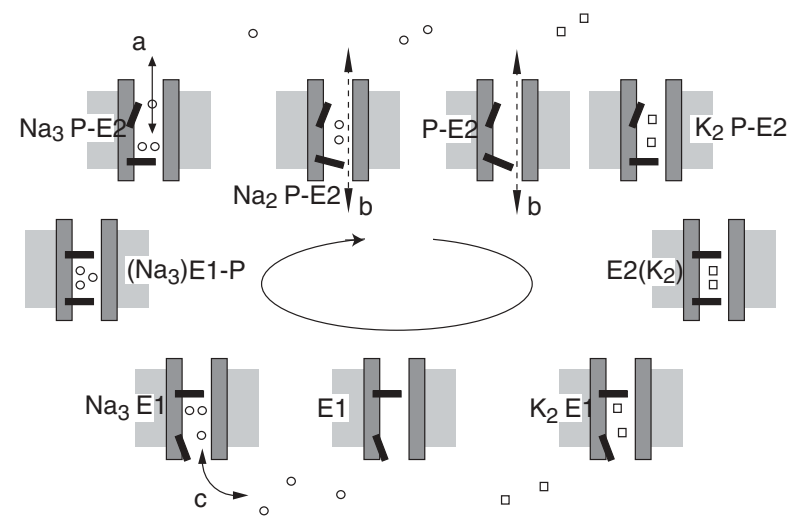

Fig. 7. Schematic model of the ion transport cycle of Na,K-ATPase. This model of the Na,K-ATPase transport cycle is shown to illustrate the steps which are affected by the mutations studied in this work. The sodium pump is represented as a channel with two gates. The naming of the states follows a more complete version of this transport cycle that can be found in Apell \& Karlish (2001) and Horisberger (2004). Small circles and squares represent $\mathrm{Na}^{+}$and $\mathrm{K}^{+}$ions, respectively. The arrow at the center indicates the physiological sense of the cycle. The largest effect concerns the electrogenic release (or rebinding) of the first $\mathrm{Na}^{+}$ions to be released to the extracellular medium (solid arrow, a). Earlier work had shown that the same mutation may also affect the affinity for intracellular $\mathrm{Na}^{+}$binding (solid arrow, c) (Li et al., 2005). The scheme also illustrates the states (phosphorylated E2, P-E2 and possibly P-E2 with $2 \mathrm{Na}^{+}$) in which the ouabain-sensitive inward current is expected to occur (dashed arrows, b).

In contrast, mutations in TM5 and TM6 produce larger alterations of the intrinsic affinity for extracellular $\mathrm{K}^{+}$. The larger effect of the mutations in TM5 and TM6 compared to the mutations in TM9 can be related to the location of $\mathrm{K}^{+}$site I close to these two membrane-spanning helices according to the model of Ogawa \& Toyoshima (2002) and to the role of several neighboring residues in these helices in $\mathrm{K}^{+}$binding according to mutagenesis experiments (Jorgensen et al., 2003). On the other hand, M9 is located much further away from $\mathrm{K}^{+}$binding sites (Fig. 1).

In the absence of extracellular $\mathrm{Na}^{+}$and $\mathrm{K}^{+}$, $\mathrm{Na}, \mathrm{K}-\mathrm{ATP}$ ase mediates a ouabain-sensitive inward current (Rakowski et al., 1991). This current is detectable at $\mathrm{pH} 7.4$ and enhanced by acidic $\mathrm{pH}$ (Wang \& Horisberger, 1995). Low extracellular $\mathrm{Na}^{+}$ concentrations $(<15-25 \mathrm{~mm})$ increase whereas higher $\mathrm{Na}^{+}$concentrations decrease the amplitude of this inward current (Efthymiadis et al., 1993; Vasilyev et al., 2004). Extracellular $\mathrm{K}^{+}$concentrations as low as $20-40 \mu \mathrm{M}$ are sufficient to activate the normal $3 \mathrm{Na}^{+} / 2 \mathrm{~K}^{+}$transport mode of the $\mathrm{Na}, \mathrm{K}$ pump, masking the inward current (Jaisser et al., 1994). Without extracellular $\mathrm{Na}^{+}$and $\mathrm{K}^{+}$, the $\mathrm{Na}, \mathrm{K}$ pump is mainly in the E2 conformation with cation binding sites exposed to the extracellular side. Wang \& Horisberger (1995) proposed that in this conformation the $\mathrm{Na}, \mathrm{K}$ pump provides a channel-like pathway for protons. Probably, the intracellular gate, which is normally closed for both $\mathrm{Na}^{+}$and $\mathrm{K}^{+}$, is somewhat "leaky" for protons. This hypothesis is consistent with more recent data concerning the $\mathrm{pH}$ effect on pre-steady-state and steady-state currents (Vasilyev et al., 2004). These authors concluded that acidification of the extracellular solution increases the opening probability of the intracellular gate of the $\mathrm{Na}, \mathrm{K}$ pump trapped in the E2P conformation, making it permeable for both $\mathrm{Na}^{+}$and protons. The state in which this inward current occurs is illustrated in the scheme of Figure 7. However, how acidic pH activates the opening of an intracellular gate remains to be clarified.

Our results show that the third $\mathrm{Na}^{+}$binding site is functionally linked to the acidic $\mathrm{pH}$-activated, ouabain-sensitive $\mathrm{Na}, \mathrm{K}$ pump-mediated current and suggest that protons which are the charge carriers of this current in the absence of extracellular $\mathrm{Na}^{+}$and $\mathrm{K}^{+}$(Vasilyev et al., 2004; Wang \& Horisberger, 1995) may use the same channel-like pathway as sodium, which moves through a high electric field pathway between its occlusion site and the extracellular solution (Apell \& Karlish, 2001; Gadsby et al., 1993; Hilgemann, 1994). These results also suggest that the third $\mathrm{Na}^{+}$-specific site is the core structure of this pathway.

Proton conduction could also be mediated by a so-called proton wire as in the well-studied gramicidin channel (Pomes \& Roux, 2002). This latter process is described as a Grotthuss mechanism in which there is no net diffusion of atomic or molecular species but, instead, the chemical exchange of hydrogen nuclei along successive hydrogen-bond donor and acceptor groups provided either by water molecules or side chains of the amino acids (Nagle \& Morowitz, 1978). In the proton wire mechanism, no channel structure is needed and conduction may occur even in the presence of a closed gate. In this case, residues in the third $\mathrm{Na}^{+}$binding site could be part of the proton wire and mutations in this site would interrupt the continuity of the proton wire. Finally, we cannot exclude the possibility that mutation in the third $\mathrm{Na}^{+}$ binding site drives the $\mathrm{Na}, \mathrm{K}$ pump into an unusual conformation which impedes indirectly the voltagedependent $\mathrm{Na}^{+}$translocation and proton current in a parallel way.

In conclusion, our results demonstrate a clear functional correlation between the proton current and the third $\mathrm{Na}^{+}$binding site of the $\mathrm{Na}, \mathrm{K}$ pump, the site responsible for the highly electrogenic extracellular $\mathrm{Na}^{+}$release/binding, suggesting that the pathway followed by the third $\mathrm{Na}^{+}$ion (the third $\mathrm{Na}^{+}$ion that does not bind to one of the two cation sites used alternatively by $\mathrm{Na}^{+}$and $\mathrm{K}^{+}$) is closely related to the proton conducting pathway. Extracellular protons and extracellular sodium may use the same pathway through a high electric field access 
channel. This finding provides new insight into the structure-function relationship of $\mathrm{Na}, \mathrm{K}-\mathrm{ATP}$ ase and opens new ways to further investigate the molecular organization of the high field channel-like pathway.

This work was supported by the Swiss National Fund (grant 31-64793.01 to K. G. and grant 31-65441.01 to J.-D. H.).

\section{References}

Apell, H.-J., Karlish, S.J.D. 2001. Functional properties of Na,KATPase, and their structural implications, as detected with biophysical techniques. J. Membr. Biol. 180:1-9

Efthymiadis, A., Rettinger, J., Schwarz, W. 1993. Inward-directed current generated by the $\mathrm{Na}^{+}, \mathrm{K}^{+}$pump in $\mathrm{Na}^{+}$- and $\mathrm{K}^{+}$-free medium. Cell Biol. Int. 17:1107-1116

Feng, J.N., Lingrel, J.B. 1995. Functional consequences of substitutions of the carboxyl residue glutamate 779 of the Na,KATPase. Cell. Mol. Biol. Res. 41:29-37

Gadsby, D.C., Rakowski, R.F., De Weer, P. 1993. Extracellular access to the Na,K pump: Pathway similar to ion channel. Science 260:100-103

Geering, K. 2001. The functional role of beta subunits in oligomeric P-type ATPases. J. Bioenerg. Biomembr. 33:425-438

Geering, K., Beggah, A., Good, P., Girardet, S., Roy, S., Schaer, D., Jaunin, P. 1996. Oligomerization and maturation of Na,KATPase - Functional interaction of the cytoplasmic NH2 terminus of the beta subunit with the alpha subunit. J. Cell Biol. 133:1193-1204

Girardet, M., Geering, K., Frantes, J.M., Geser, D., Rossier, B.C., Kraehenbühl, J.-P 1981. Immunochemical evidence for a transmembrane orientation of both the $\mathrm{Na}^{+}, \mathrm{K}^{+}$-ATPase subunits. Biochemistry 20:6684-6691

Hakansson, K.O., Jorgensen, P.L. 2003. Homology modeling of $\mathrm{Na}, \mathrm{K}-\mathrm{ATPase}$ - A putative third sodium binding site suggests a relay mechanism compatible with the electrogenic profile of $\mathrm{Na}^{+}$translocation. Na,K-ATPase Relat. Cation Pumps 986: $163-167$

Hilgemann, D.W. 1994. Channel-like function of the Na,K pump probed at microsecond resolution in giant membrane patches. Science 263:1429-1432

Horisberger, J.-D 2004. Recent insights into the structure and mechanism of the sodium pump. Physiology 19:377-387

Horisberger, J.-D., Kharoubi-Hess, S. 2002. Functional differences between $\alpha$ subunit isoforms of the rat Na,K-ATPase expressed in Xenopus oocytes. J. Physiol. 539:669-680

Horisberger, J.-D., Kharoubi-Hess, S., Guennoun, S., Michielin, O. 2004. The 4th transmembrane segment of the Na,K-ATPase $\alpha$ subunit: A systematic mutagenesis study. J. Biol. Chem. 279:29542-29550

Jaisser, F., Jaunin, P., Geering, K., Rossier, B.C., Horisberger, J.-D 1994. Modulation of the Na,K-pump function by the $\beta$-subunit isoforms. J. Gen. Physiol. 103:605-623

Jewell-Motz, E.A., Lingrel, J.B. 1993. Site-directed mutagenesis of the Na,K-ATPase: Consequences of substitutions of negatively- charged amino acids localized in the transmembrane domains. Biochemistry 32:13523-13530

Jorgensen, P.L., Hakansson, K.O., Karlish, S.J.D. 2003. Structure and mechanism of Na,K-ATPase: Functional sites and their interactions. Annu. Rev. Physiol. 65:817-849

Läuger, P., 1991. Na,K-ATPase. In: Electronic Ion Pumps, Sinauer Associates, Sunderland, MA 168-225

Li, C., Capendeguy, O., Geering, K., Horisberger, J.-D 2005. A third $\mathrm{Na}^{+}$binding site in the sodium pump. Proc. Natl. Acad. Sci. USA 102:12706-12711

Melton, D.A., Krieg, P.A., Rebagliati, M.R., Maniatis, T., Zinn, K., Green, M.R. 1984. Efficient in vitro synthesis of biologically active RNA and RNA hybridization probes from plasmids containing a bacteriophage SP6 promoter. Nucleic Acids Res. 12:7035-7056

Nagle, J.F., Morowitz, H.J. 1978. Molecular mechanisms for proton transport in membranes. Proc. Natl. Acad. Sci. USA 75:298-302

Nelson, R.M., Long, G.L. 1989. A general method of site-specific mutagenesis using a modification of the Thermus aquaticus polymerase chain reaction. Anal. Biochem. 180:147-151

Ogawa, H., Toyoshima, C. 2002. Homology modeling of the cation binding sites of the $\mathrm{Na}^{+} \mathrm{K}^{+}$-ATPase. Proc. Natl. Acad. Sci. USA 99:15977-15982

Pomes, R., Roux, B. 2002. Molecular mechanism of $\mathrm{H}^{+}$conduction in the single-file water chain of the gramicidin channel. Biophys. J. 82:2304-2316

Post, R.L., Jolly, P.C. 1957. The linkage of sodium, potassium, and ammonium active transport across the human erythrocyte membrane. Biochim. Biophys. Acta 25:118-128

Rakowski, R.F., Vasilets, L.A., LaTona, J., Schwarz, W. 1991. A negative slope in the current-voltage relationship of the $\mathrm{Na}^{+} /$ $\mathrm{K}^{+}$pump in Xenopus oocytes produced by reduction of external $\left[\mathrm{K}^{+}\right.$]. J. Membr. Biol. 121:177-187

Rettinger, J. 1996. Characteristics of $\mathrm{Na}^{+} / \mathrm{K}^{+}$-ATPase mediated proton current in $\mathrm{Na}^{+}$- and $\mathrm{K}^{+}$-free extracellular solutions Indications for kinetic similarities between $\mathrm{H}^{+} / \mathrm{K}^{+}$-ATPase and $\mathrm{Na}^{+} / \mathrm{K}^{+}$-ATPase. Biochim. Biophys. Acta 1282:207-215

Sweadner, K.J., Donnet, C. 2001. Structural similarities of Na,KATPase and SERCA, the $\mathrm{Ca}^{2+}$-ATPase of the sarcoplasmic reticulum. Biochem. J. 356:685-704

Toyoshima, C., Mizutani, T. 2004. Crystal structure of the calcium pump with a bound ATP analogue. Nature 430:529-535

Toyoshima, C., Nakasako, M., Nomura, H., Ogawa, H. 2000. Crystal structure of the calcium pump of sarcoplasmic reticulum at 2.6 A resolution. Nature 405:647-655

Toyoshima, C., Nomura, H. 2002. Structural changes in the calcium pump accompanying the dissociation of calcium. Nature 418:605-611

Van Huysse, J.W., Jewell, E.A., Lingrel, J.B. 1993. Site-directed mutagenesis of a predicted cation binding site of $\mathrm{Na}, \mathrm{K}-\mathrm{ATPase}$. Biochemistry 32:819-826

Vasilyev, A., Khater, K., Rakowski, R.F. 2004. Effect of extracellular $\mathrm{pH}$ on presteady-state and steady-state current mediated by the $\mathrm{Na}^{+} / \mathrm{K}^{+}$pump. J. Membr. Biol. 198:65-76

Wang, X., Horisberger, J.-D 1995. A conformation of the Na,Kpump is permeable to proton. Am. J. Physiol. 37:C590-C595 